References: None

Disclosure of Interests: Takeshi Suzuki Speakers bureau: Abbvie, Asahi-kasei, Astellas, Bristol-Myers Squibb, Chugai, Eli Lilly, Mitsubishi-Tanabe, Novartis, UCB, Harumi Shirai: None declared

DOI: 10.1136/annrheumdis-2020-eular.1944

\section{SAT0571 OPTICAL SPECTRAL TRANSMISSION TO ASSESS THERAPY RESPONSE IN PATIENTS WITH ARTHRITIS: A COMPARATIVE STUDY WITH CLINICAL, LABORATORY AND ULTRASONOGRAPHIC ACTIVITY MARKERS.}

K. Triantafyllias ${ }^{1}$, C. Heller ${ }^{2}$, M. De Blasi ${ }^{1}$, M. Muthuraman ${ }^{3}$, A. Schwarting ${ }^{1,2}$. ${ }^{1}$ ACURA Clinics, Rheumatology, Bad Kreuznach, Germany; ${ }^{2} J o h a n n e s$ Gutenberg University Medical Center, Internal Medicine I, Deparmtnet of Rheumatology and Clinical Immunology, Mainz, Germany; ${ }^{3} J o h a n n e s$ Gutenberg University Medical Center, Biomedical Statistics and Multimodal Signal Processing, Mainz, Germany

Background: Valid assessment of disease activity leads to outcome improvement in patients with rheumatoid arthritis (RA) (1). Optical spectral transmission (OST) is a modern diagnostic tool able to assess the blood-specific absorption of light transmitted through a tissue, promising quantification of inflammation in the finger and wrist joints of RA patients (commercial device: HandScan - Hemics, The Netherlands) (2).

Objectives: To our knowledge, there are no data regarding the diagnostic value of OST in the evaluation of inflammatory activity changes during arthitis follow up. Thus, aims of this study were to examine the ability of OST to detect response to anti-inflammatory therapy in patients with arthritis and to explore OST associations with clinical, laboratory and ultrasonographic (US) activity markers.

Methods: OST measurements were performed in patients with active arthritides of the wrist and finger joints before and after administration of glucocorticoids (GC), during a disease flare. For the same points in time ( $a$ and $b$ ) patients and healthy controls underwent clinical, laboratory and joint US [Grey Scale (GSUS) Power Doppler (PDUS)] examinations. OST-values before and after therapy were subsequently compared with their corresponding DAS28- and US-values. The distributions of Delta-PDUS und OST-values between the two time points were compared by Bayesian statistics. Moreover, OST diagnostic performance was tested by Receiver Operating Characteristics (ROC).

Results: We recruited 54 patients with active inflammatory arthritis: 39 RA, 4 gout, 7 peripheral spondylarthritides and 4 other miscellaneous arthritides (66.7\% females) and 114 controls.

Previous to therapy with GC, median OST was [OST(a): 8.75 (5.38-16.25, IQR)] and after therapy [OST(b): $4.75(2.38-8.63, \mathrm{IQR})](p<0.05)$. Similarly, DAS28 dropped significantly after GC therapy [DAS28(a): 5.12 (4.33-6.10, IQR) vs. DAS28(b): 3.85 (3.40-4.82), $p<0.05)$ ]. OST correlated moderately with PDUS at both time points: (a) $r h o=0.449$ and (b) $r h o=0.414$, respectively (both; $p<0.01$ ). Moreover, OST correlated significantly with swollen joint count at both time points (a) $r h o=0.379$ and (b) $r h o=0.382, p<0.01$ respectively.

OST and US performed similarly in the assessment of inflammatory changes caused by the administration of GC (same tendency in the change of OST values in $83.2 \%$ of the cases). Furthermore, Bayesian statistic revealed no significant differences between OST and US for all 3 examined joint categories (MCP: $p=0.81$; PIP: $p=0.74$; wrists: $p=0.60$ ).

In addition, ROC revealed that OST is a very good tool to distinguish patients with arthritis from healthy controls at both examination points [AUC(a): 0.883(95\% $\mathrm{Cl}=0.83-0.94)$ and $\mathrm{AUC}(\mathrm{b}): 0.811(95 \% \mathrm{Cl}=0.74-0.881)]$.

Conclusion: OST was able to assess response to therapy in arthritis patients comparable to US. Moreover, OST correlated with disease activity markers and could effectively differentiate between arthritis patients and controls. Therefore, OST could prove to be a valuable non-interventional time- and resource-saving diagnostic tool to assist arthritis monitoring.

References:

[1] Katchamart W, et al. Systematic monitoring of disease activity using an outcome measure improves outcomes in rheumatoid arthritis. J Rheumatol 2010;37:1411-1415.

[2] Onna M Van, et al. Assessment of disease activity in patients with rheumatoid arthritis using optical spectral transmission measurements, a non-invasive imaging technique. Ann Rheum Dis 2016;75:511-518.

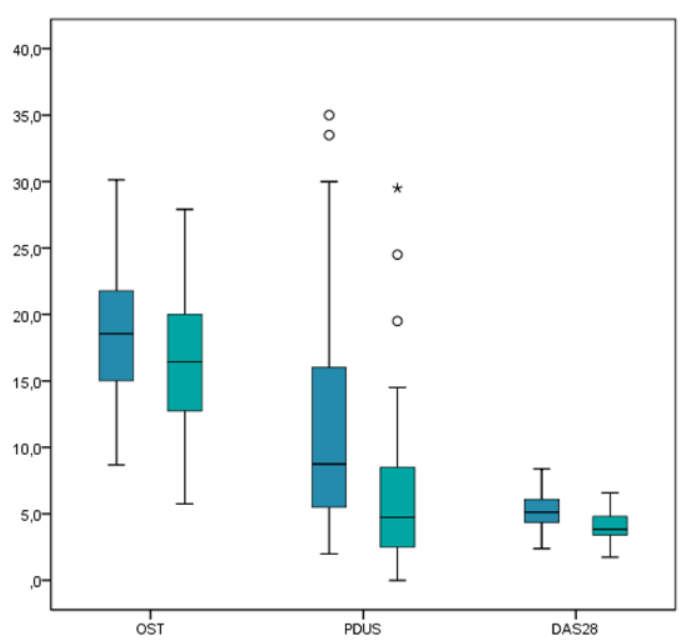

Figure 1. OST-, PDUS- and DAS28- values before and after GC therapy.
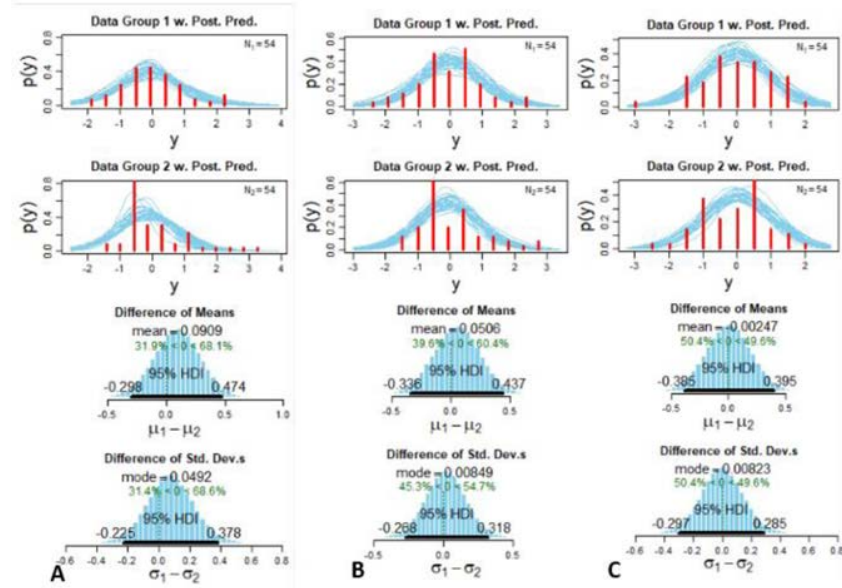

Figure 2. OST- (group 1) und Ultrasound- (group 2) Bayesian distributions, means- and standard deviation-differences for MCP (A), PIP (B) and wrists (C).

Disclosure of Interests: None declared

DOI: 10.1136/annrheumdis-2020-eular.3028

\section{SAT0572 CONSTRUCTIVE VALIDITY OF MUSKULOSKELETAL ULTRASOUND MEASUREMENT OF CARTILAGE THICKNESS IN PATIENTS WITH KNEE OSTEOARTHRITIS}

Z. Velickovic ${ }^{1}$, S. Janjic ${ }^{1}$, V. Bajec ${ }^{1}$, B. Stojic ${ }^{1}$, T. Zivanovic Radnic ${ }^{1,2}$, M. Rasic ${ }^{1}$, G. Radunovic ${ }^{1,2} .{ }^{1}$ Institute of Rheumatology, Belgrade, Serbia; ${ }^{2}$ School of Medicine, University of Belgrade, Belgrade, Serbia

Background: Cartilage thickness is one important measure in describing both OA development and progression. Based on current knowledge, conventional radiography $(\mathrm{CR})$ and magnetic resonance imaging (MRI) have not been demonstrated to be superior over one another. Because of disadvantages of MRI and $C R$ neither can be use in routine daily clinical practice for follow up of OA patients. Diagnostic ultrasound assessment (US) of cartilage thickness offers an alternative measure as a clinically available and more cost-effective source of knee articular cartilage imaging.

Objectives: Our objective was to determine the relationship between US and CR measures of femoral cartilage thickness in patients with knee osteoarthritis because systematic feature- and site-specific cross-comparison between this two methods is still missing in the current literature.

Methods: 120 patients with knee osteoarthritis (240 knees) are recruited for this study. The joint space width (JSW) and Kellgren and Lawrence (K\&L) grade were measured using weight-bearing anteroposterior $30^{\circ}$ knee semi-flexion knee radiography (with inclusion criteria K\&L grade 1-4). Femoral cartilage thickness was measured three times in supine position and with a suprapatellar transverse scan with the knee in maximal flexion at the lateral condyle (LC), medial condyle (MC) and intercondylar notch (IN) by one rheumatologist and arithmetic mean is taken. Pain and 
functionality are measured with VAS pain scale, Womac, Lysholm and SF 36 score. The agreement between two methods was evaluated with Bland-Altman analysis. Results: We found a statistically significant low level of rank correlation between CR and US measurements of mean cartilage thickness; $\rho$ (rho) values between modalities were low ( 0.263 and 0.273 depending on side (right/left), $p=0.005$ and $\mathrm{p}=0.007$ respectively). In Bland - Altman analysis, US measurement showed bad agreement with CR. Presence or absence of US features of OA (effusion, synovial hypertrophy, osteophytes and popliteal cysts) didn't influence on cartilage thickness assessed by US ( $p>0.05$ ). For US assessment, we found correlation only between cartilage thickness and VAS pain scale ( $\rho$ (rho) $-0.281, p=0.004$ ). We didn't found any statistically significant correlation between CR thickness measures and pain/functionality/HRQoL scores ( $p>0.05$ ).

Conclusion: These results suggest that ultrasound may be a useful clinical tool to assess relative cartilage thickness. However, the absolute validity of the ultrasound measure is called into question due to the larger CR-based thickness measures and low level of agreement according to Bland-Altman analysis. The use of ultrasound as a complementary imaging tool along with CR may enable more accurate and cost-effective detection, prognosis and follow-up of knee osteoarthritis in routine clinical practice.

References:

[1] Mehta N, Duryea J, Badger GJ, et al. Comparison of 2 Radiographic Techniques for Measurement of Tibiofemoral Joint Space Width. Orthop J Sports Med. 2017;5:2325967117728675.

[2] Schmitz RJ, Wang HM, Polprasert DR, Kraft RA, Pietrosimone BG. Evaluation of knee cartilage thickness: A comparison between ultrasound and magnetic resonance imaging methods. Knee. 2017;24:217-223.

[3] Podlipská J, Guermazi A, Lehenkari P, et al. Comparison of Diagnostic Performance of Semi-Quantitative Knee Ultrasound and Knee Radiography with MRI: Oulu Knee Osteoarthritis Study. Sci Rep. 2016;6:22365

[4] Razek AA, El-Basyouni SR. Ultrasound of knee osteoarthritis: interobserver agreement and correlation with Western Ontario and McMaster Universities Osteoarthritis. Clin Rheumatol. 2016;35:997-1001.

[5] Oo WM, Bo MT. Role of Ultrasonography in Knee Osteoarthritis. J Clin Rheumatol. 2016;22:324-329.

Disclosure of Interests: None declared

DOI: 10.1136/annrheumdis-2020-eular.3049

\section{SATURDAY, 06 JUNE 2020 \\ Epidemiology, risk factors for disease or disease progression}

\section{SAT0573 \\ TUBERCULOSIS INFECTION IN MOROCCAN PATIENTS WITH RHEUMATIC DISEASES UNDER BIOLOGIC THERAPY: A MULTICENTER NATIONAL STUDY}

I. Aachari ${ }^{1}$, T. Latifa ${ }^{1}$, T. Fatima Zahrae ${ }^{1}$, S. Afilal ${ }^{1}$, F. Safaa ${ }^{1}$, J. Moulay Berkchi ${ }^{1}$, H. Rkain ${ }^{1,2}$, F. Allali ${ }^{1} .{ }^{1}$ El Ayachi Hospital, Rheumatology, Salé, Morocco;

${ }^{2}$ Laboratory of Physiology, Faculty of Medicine and Pharmacy, Mohammed V University, Rabat, Morocco

Background: Tuberculosis (TB) is a major health problem worldwide, occurring mainly in low income countries. Therefore, screening for latent TB infection (LTBI) before initiating biologic therapy is mandated by current guidelines.

Objectives: The aim of this study was to evaluate the prevalence of tuberculosis infection (TB) in Moroccan patients with rheumatic diseases under biologic therapy, and to describe the demographic characteristics of these patients as well as to explore potential risk factors.

Methods: This fourteen-year nationally representative multicenter study enrolled Moroccan patients with rheumatic diseases who had been treated with biologic therapy. Patient medical records were reviewed retrospectively for demographic characteristics, underlying rheumatic diseases, associated co-morbidities, and TB related data.

Results: In total, 1407 eligible patients were studied; 31 cases with active TB were identified at an estimated prevalence rate of $2.3 \%$. The mean age was $42.9 \pm 12$ years and $75.8 \%$ were males. Ankylosing spondylitis (AS) accounted for $84.8 \%$ of active TB cases and the majority of cases (31/33) occurred among anti TNF-a users. A total of 8 out of 33 patients were positive at initial Latent TB infection (LTBI) screening by tuberculin skin test (TST) and/ or interferon gamma release assay (IGRA). Consumption of unpasteurized dairy products (odds ratio [OR], 34,841; 95\% Cl, 3,1-389,7; $\mathrm{p}=0,04)$, diabetes (OR, 38,468; 95\% Cl, 1,6$878,3$; $p=0,022)$, smoking (OR, 3,941; $95 \% \mathrm{Cl}, 1-159,9 ; \mathrm{p}=0,047)$ and long biologic therapy duration $(\mathrm{OR}, 1,991 ; 95 \% \mathrm{Cl}, 1,4-16,3 ; \mathrm{p}=0,001)$ were identified as risk factors for developing active TB.

Conclusion: Moroccan patients with rheumatic diseases under anti TNF- a agents are at an increased TB risk especially when risk factors are present. Strict initial screening and regular monitoring of LTBI is recommended for patients living in high TB prevalence areas.
Table 1. Risk factors by univariate and multivariate logistic regression.

\section{Disclosure of Interests: None declared}

\begin{tabular}{|c|c|c|c|c|c|c|}
\hline \multirow{2}{*}{ Variables } & \multicolumn{3}{|c|}{ Univariate analysis } & \multicolumn{3}{|c|}{ Multivariate analysis } \\
\hline & Odds Ratio & $95 \%$ CI & $p$ value & Odds Ratio & $95 \%$ CI & $p$ value \\
\hline Age & 0,999 & $0,97-1,028$ & 0,929 & & & \\
\hline Sexe & 0,973 & $0,388-2,443$ & 0,954 & & & \\
\hline $\begin{array}{c}\text { Marital status : } \\
\quad \begin{array}{l}\text { Married } \\
\text { Single }\end{array}\end{array}$ & $\begin{array}{l}0,593 \\
1,685\end{array}$ & $\begin{array}{l}0,259-1,357 \\
0,737-3,855\end{array}$ & $\begin{array}{l}0,216 \\
0,216\end{array}$ & & & \\
\hline $\begin{array}{c}\text { Residence : } \\
\text { : Urban } \\
\text { - Rural }\end{array}$ & $\begin{array}{l}0,778 \\
1,286\end{array}$ & $\begin{array}{l}0,189-3,199 \\
0,313-5,288\end{array}$ & $\begin{array}{l}0,728 \\
0,728\end{array}$ & & & \\
\hline $\begin{array}{c}\text { Level of education : } \\
\text { - Mliterate } \\
\text { : Primary } \\
\text { : Secondary } \\
\text { Tertiary }\end{array}$ & $\begin{array}{l}1,313 \\
2,370 \\
0,918 \\
1,123\end{array}$ & $\begin{array}{l}0,547-3,150 \\
0,797-7,047 \\
0,314-2,683 \\
0,345-3,649\end{array}$ & $\begin{array}{l}0,542 \\
0,121 \\
0,875 \\
0,847\end{array}$ & & & \\
\hline $\begin{array}{l}\text { Consumption of unpasteurized } \\
\text { dairy products }\end{array}$ & 3,571 & $1,531-8,330$ & 0,03 & 34,841 & $3,1-389,7$ & 0,04 \\
\hline Diabetes & 5,145 & $1,140-23,211$ & 0,033 & 38,468 & $1,6-878,3$ & 0,022 \\
\hline Smoking & 3,667 & $1,311-10,253$ & 0,013 & 3,941 & $1-159,9$ & 0,047 \\
\hline $\begin{array}{l}\text { Type of rheumatic disease : } \\
\text { : Ankyosing spondylitis } \\
\text { Rheumatoid arthritis }\end{array}$ & $\begin{array}{c}0,276 \\
0\end{array}$ & $0,97-0,781$ & $\begin{array}{l}0,15 \\
0,999\end{array}$ & & & \\
\hline $\begin{aligned} \text { Biologic therapy : } \\
\text { : Adalimumab } \\
\text { Infliximab } \\
\text { : Etanercept } \\
\text { : Tocilimab } \\
\text { : Golimumab } \\
\text { : Secukinumab }\end{aligned}$ & $\begin{array}{c}1,151 \\
1,340 \\
2,29 \\
0,272 \\
0,223 \\
0,979 \\
0 \\
\end{array}$ & $\begin{array}{c}0,511-2,593 \\
0,583-3,079 \\
0,675-7,804 \\
0,033-2,210 \\
0,033-2,210 \\
0,098-9,751 \\
\end{array}$ & $\begin{array}{l}0,734 \\
0,491 \\
0,183 \\
0,223 \\
0,223 \\
0,986 \\
0,999 \\
\end{array}$ & & & \\
\hline $\begin{array}{l}\text { Duration of exposure to } \\
\text { bDMARD (months) }\end{array}$ & 1,462 & $1,261-1,695$ & $<0,001$ & 1,991 & $1,4-16,3$ & 0,001 \\
\hline
\end{tabular}

DOI: 10.1136/annrheumdis-2020-eular.1616

\section{SAT0574 \\ RISK FACTORS ASSOCIATED WITH OPIOID USE AMONG WORKER'S COMPENSATION: A LITERATURE REVIEW}

M. Agalioitis ${ }^{1}$, A. Sran ${ }^{2} .{ }^{1}$ Australian Institute of Health Service Management (AlHSM), University of Tasmania, Rozelle Campus, Australia; ${ }^{2}$ University of New South Wales, School of Public Health \& Community Medicine, Kensington, Australia

Background: To increase recovery and return to work after an occupational accident or injury, a worker's compensation claim provides individualised management plan involving multiple kinds of treatment. These plans can consist of the prescription of opioids to reduce inflammation, provide pain relief and increase functionality within a short period of time to aid return to work. Recently, there have been growing concerns about the misuse of opioids in managing pain symptoms by both the insurance industry and the general community. Studies from North America have indicated the prescription and management of opioid consumption among workers compensation claimants can cause more harm to functionality and reduce recovery to return to work, often leading to misuse, dependency or overdosing (Dembe, Wickizer, Sieck, Partridge \& Balchick (2012)].

Objectives: The aims of this abstract are to provide a comprehensive literature review of the studies that have examined: 1 ) the prevalence of opioid use among worker compensations claimants and, 2) identify predictors of long-term opioid use among the workers compensation claimants.

Methods: A search strategy, with terms associated with "worker compensation", "opioids" "prevalence" and/or "risk factors" were used to search through relevant databases such as CINAHL, Cochrane, Embase, MEDLINE, PsycINFO, Scopus and Web of Science from database inception to January 2020. Duplicates were excluded. Two researchers retrieved, screened for eligibility and reviewed the results accordingly using a staged approach. Systematic review registration number PROSPERO registry number: CRD42013004137.

Results: The search yielded 2857 records. After the initial screening, 125 fulltext articles were assessed by two independent reviewers. The inclusion criteria were met by nine studies1-9. All studies conducted retrospective cohort studies using workers compensation claimant's data, ranging from 54,931, to 100,357 reports, either over a short 12-month period to over 11 years, with no reporting of response rate or recruitment rates. All studies examined the association of being exposure to opioids from the date of the workers injury(7), ranging from 30 to 730 days or from 0 days to 4 or more years $14-9$. Carnide et al (2018)2 was the only study to investigate opioid exposure before and after injury as a predictor of future long term use. Among those who examined work-opioid related factors (4) found workers compensation reports with work disability for more than 14 days where more likely to become a long term opioid uses (OR: 2.17 [95\% Cl:1.523.10])1. Kraut et al7 on the other hand, found being a worker's compensation claimant increased the risk of being prescribed $\geq 120$ morphine equivalents (ME) 